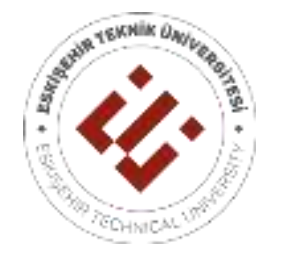

ESKISSEHIR TECHNICAL UNIVERSITY JOURNAL OF SCIENCE AND TECHNOLOGY A- APPLIED SCIENCES AND ENGINEERING

8th International Fiber and Polymer Research Symposium

(8th ULPAS) - Special Issue 2021

2021, Vol.22 Pp. 1-9, DOI:10.18038/estubtda.976016

\title{
COMPRESSION AND INTERLAMINAR SHEAR PROPERTIES OF NANOPARTICLE DOPED HYBRID NANOFIBER INTERLEAVED GLASS/EPOXY COMPOSITES
}

\author{
Fatih METiN ${ }^{1, *(D)}$, Ahmet AVCI ${ }^{2}$ \\ ${ }^{1}$ Department of Metallurgical and Materials Engineering, Konya Technical University, 42075, Konya, Turkey \\ ${ }^{2}$ Department of Biomedical Engineering, Necmettin Erbakan University, 42140, Konya, Turkey
}

\begin{abstract}
The effects of $\mathrm{SiC}_{-} \mathrm{Fe}_{3} \mathrm{O}_{4}$ nanoparticles doped electrospun Polysulfone (PSF) nanofibers on compressive and interlaminar shear strength of glass/epoxy composite laminates were investigated in this study. Pure PSF and hybrid PSF nanofibers were produced by the electrospinning process. Nanofiber interleaved glass/epoxy composite laminates were manufactured by using a vacuum-assisted hand-lay-up method. The addition of $\mathrm{SiC}-\mathrm{Fe}_{3} \mathrm{O}_{4}$ nanoparticles into PSF nanofibers improved the tensile properties of nanofiber mats. The results revealed that PSF hybrid nanofiber interleaving increased the compressive and interlaminar shear strengths of composite laminates up to $26 \%$ and $12.4 \%$, respectively.
\end{abstract}

Keywords: Electrospinning, Nanofiber interleaving, Mechanical testing, Composite laminates

\section{INTRODUCTION}

Fiber-reinforced polymer composites have superior material properties like strength-to-weight ratio, stiffness-to-weight ratio, and low density compared to traditional metallic materials. Therefore, they are used widely in aircraft, automotive, marine, and many other industrial applications to reduce weight and improve structural performance $[1,2]$. However, the coexistence of brittle epoxy matrix and the anisotropic nature of fiber-reinforced composites can lead to unexpected damages growing with intra-ply cracks, delamination, and fiber failure, respectively. Delamination occurring in the resin-rich interlaminar region is one of the most common damages in fiber-reinforced polymer composites [3, 4].

In recent years, thermoplastic nanofiber interleaving, first introduced by Dzenis and Reneker [5], has become an attractive technique to enhance the toughness of weak interlaminar regions in fiberreinforced composites. Thermoplastic nanofibers are produced by the electrospinning method and accumulated on a separate surface or directly fabric layer. Having diameters in nanoscales, tiny thickness with a porous structure, and a very high area to volume ratio are the superior properties of electrospun nanofibers [6, 7]. Many studies have been reported that PA6.6 [3, 8], PAN [6, 9], PVDF [10], PVA [11], PSF [12-15] nanofibers interleaving improved the mechanical properties of fiberreinforced composites. These entangled nanofibers act like the hoops and loops in Velcro to enhance interlaminar toughness and take an active role in interlaminar toughening mechanisms like crack bridging, crack deflection, plastic deformation, and nanofiber pull- out [16]. Beylergil, et al. [8] carried out three-point bending, tensile, compression, Charpy impact, interlaminar shear strength, and DCB (Double cantilever beam) tests on reference and nanofiber reinforced carbon/epoxy composites to examine the effects of PA 6.6 nanofibers on mechanical properties. They revealed that PA 6.6 nanofibers improved flexural modulus by $16 \%$, flexural strength by $13 \%$, compression strength by $15 \%$, and Charpy impact strength by $18 \%$, while a $10 \%$ decrease in the tensile strength. Li, et al. [13] used PSF films and nanofibers for increasing Mode I fracture toughness of carbon /epoxy composites. The results showed that PSF nanofiber interleaving improved the Mode I fracture toughness by $140 \%$

*Corresponding Author: fatihmetin64@gmail.com

Received: 03.08.2021 Published: 30.11.2021 
and $280 \%$ compared to film interleaved and untoughened composite laminates. Anand, et al. [17] showed that interleaved Nylon 6/6 nanofibers with an areal density of 0.4 gsm could increase compressive and interlaminar shear strengths by $30 \%$ and $17 \%$, respectively, in glass/epoxy composites.

The addition of nanoparticles into electrospun nanofibers can further increase the mechanical strengths of nanofiber mats and nanofiber interleaved polymer matrix composites. Liu, et al. [18] observed no significant change in diameter and morphological properties of PLGA/MWCNT composite nanofibers with $1 \mathrm{wt} \%$ MWCNT compared to pure PLGA nanofibers. Moreover, the addition of $1 \mathrm{wt} \%$ MWCNT improved the tensile strength and Young's modulus of nanofibers by $49 \%$ and $88 \%$, respectively. $\mathrm{Li}$, et al. [14] studied the effects of $5 \mathrm{wt} \%, 10 \mathrm{wt} \%, 15 \mathrm{wt} \%$, and $20 \mathrm{wt} \%$ MWCNT-EP/PSF hybrid nanofibers on flexural, interlaminar shear strength (ILSS), and Mode II fracture toughness on carbon/epoxy composite laminates. They observed that $20 \mathrm{wt} \%$ MWCNT-EP/PSF hybrid nanofibers increased the flexural strength and modulus by $13.3 \%$ and $22.8 \%$, respectively, compared to PSF toughened laminates. The results showed that the ILSS of $20 \mathrm{wt} \%$ MWCNT-EP/PSF hybrid nanofiber toughened laminates was $11.9 \%$ higher than the reference laminates. The best improvement of Mode II fracture toughness was achieved in $10 \mathrm{wt} \%$ MWCNT-EP/PSF hybrid nanofiber toughened laminates, compared to PSF toughened laminates.

In the literature, no study has been found examining the effects of $\mathrm{SiC}-\mathrm{Fe}_{3} \mathrm{O}_{4}$ nanoparticle doped PSF hybrid nanofiber interleaving on the mechanical performance of glass/epoxy composites. This study aims to improve the compressive strength and interlaminar shear strength of glass/epoxy composites by incorporating pure PSF nanofibers, $1 \mathrm{wt} \%$, and $2 \mathrm{wt} \% \mathrm{SiC}_{-} \mathrm{Fe}_{3} \mathrm{O}_{4} / \mathrm{PSF}$ hybrid nanofibers between plies.

\section{EXPERIMENTAL}

\subsection{Material}

Polysulfone (PSF) pellets were purchased from Sigma-Aldrich. Acetone (AC) and Dimethylacetamide (DMAC) were used as solvents of PSF pellets. $\mathrm{SiC}$ and $\mathrm{Fe}_{3} \mathrm{O}_{4}$ nanoparticles were supplied from Nanografi. 2/2 twill weave E-glass woven fabrics having $390 \mathrm{~g} / \mathrm{m}^{2}$ areal weight were provided from Hexcel. Epoxy resin (MGS L 160) and curing agent (MGS H 160) were obtained from Hexion.

\subsection{Method}

Three different polymeric solutions were prepared for the electrospinning process. For the first solution, $20 \mathrm{wt} \%$ PSF pellets were dissolved in a mixture of DMAC/AC $(9: 1 \mathrm{w} / \mathrm{w})$ on a magnetic stirrer at $70^{\circ} \mathrm{C}$ for 5 hours for pure PSF solution. For the second and third solutions, $1 \mathrm{wt} \%$ and 2 wt $\% \mathrm{SiC}-\mathrm{Fe}_{3} \mathrm{O}_{4}$ nanoparticles by PSF weight were separately dispersed in the mixture of DMAC/AC $(9: 1 \mathrm{w} / \mathrm{w})$ using an ultrasonic sonicator for 10 minutes. Then, $20 \mathrm{wt} \%$ PSF pellets were dissolved in each mixture using the magnetic stirrer at $70^{\circ} \mathrm{C}$ for 5 hours. At the last step, $\mathrm{SiC}-\mathrm{Fe}_{3} \mathrm{O}_{4}$ nanoparticles doped solutions were sonicated for 10 minutes at room temperature. Each PSF solution was withdrawn into four syringes and positioned on the syringe pump for electrospinning. The main parts of a typical electrospinning setup are shown in

Figure 1. The electrospinning process was performed at $26-32 \mathrm{kV}$ applied voltage, $13 \mathrm{~cm}$ tip to collector distance, $1.5 \mathrm{ml} / \mathrm{h}$ feeding rate, and $600 \mathrm{rpm}$ collector speed. 


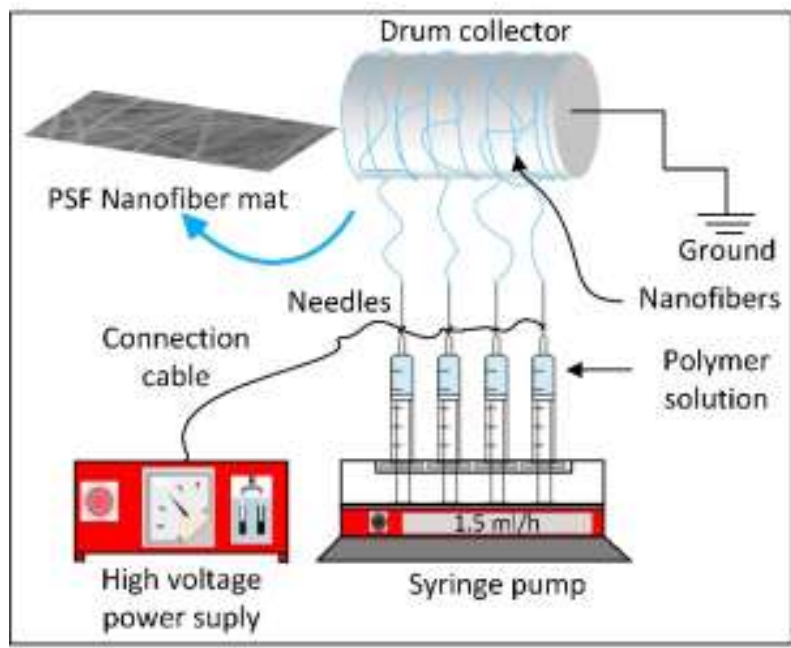

Figure 1. Schematic illustration of the electrospinning setup

Reference (non-interleaved), pure PSF interleaved, $1 \mathrm{wt} \%$ and $2 \mathrm{wt} \% \mathrm{SiC}-\mathrm{Fe}_{3} \mathrm{O}_{4} / \mathrm{PSF}$ interleaved composite laminates having eight plies of E-glass fabrics were manufactured using the vacuumassisted hand lay-up method. Nanofiber mats with $160 \mathrm{~mm}$ x $300 \mathrm{~mm}$ in size were incorporated into each successive ply. After completing the hand lay-up process, the whole system sealed by a vacuum bag was vacuumed under 0.85 bar pressure for 1.5 hours to remove the excess epoxy resin and air bubbles, and then cured at $45^{\circ} \mathrm{C}$ for 6 hours followed by $80{ }^{\circ} \mathrm{C}$ for 8 hours.

Tensile tests of pure PSF, $1 \mathrm{wt} \%$ and $2 \mathrm{wt} \% \mathrm{SiC}-\mathrm{Fe}_{3} \mathrm{O}_{4} / \mathrm{PSF}$ nanofiber mats were conducted with a Shimadzu AGS-X table-top universal testing machine having a $10 \mathrm{~N}$ load cell at the cross-head speed of $12 \mathrm{~mm} / \mathrm{min}$.

Figure 2 shows the preparation of tensile test strips of nanofiber mats and tensile test setup. Nanofiber mats were cut into strips $10 \mathrm{~mm} \times 50 \mathrm{~mm}$ in size. Tensile test strips were glued to a paper square frame with double-sided tapes to protect the nanofibers from damage while mounting in the tensile grips. The paper frames were cut with scissors just before starting the test.

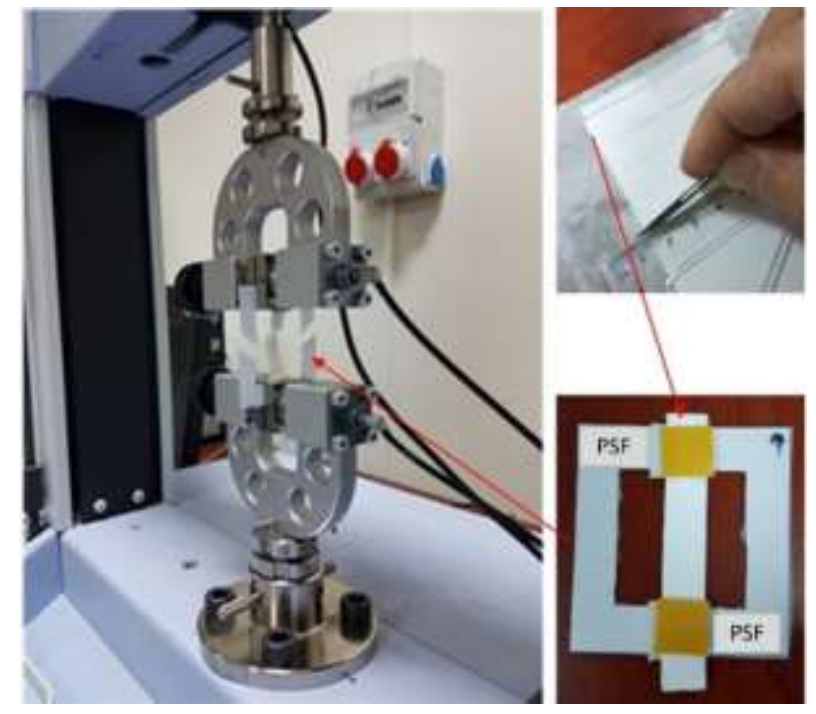

Figure 2. Preparation of tensile test strips of nanofiber mats and tensile testing 
Compression and interlaminar shear tests of composite laminates were conducted with Shimadzu AGS-X Universal testing machine with a $100 \mathrm{kN}$ load cell at the cross-head speed of $1.3 \mathrm{~mm} / \mathrm{min}$. Reference and nanofiber interleaved composite laminates were cut into specimens' dimensions to determine compressive and interlaminar shear strengths according to ASTM D695 and ASTM D3846. Figure 3 shows the specimen dimensions with double notches according to ASTM D3846 and the antibuckling fixture used in compression and interlaminar shear strength tests. Interlaminar shear strength was calculated by dividing the maximum compression load by the interlaminar surface area (specimen width $\mathrm{x}$ the length between notches).
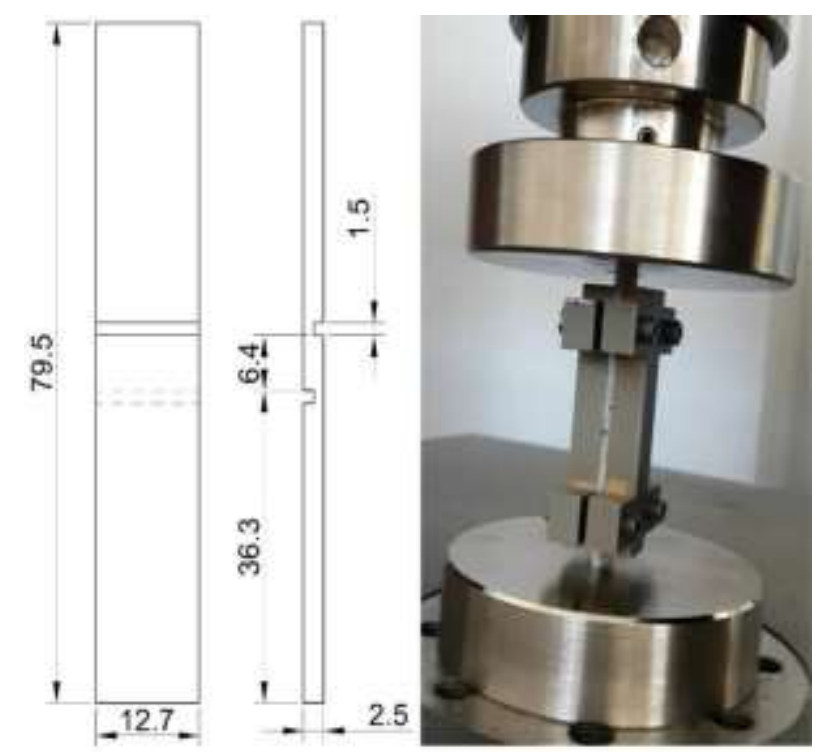

Figure 3. Interlaminar shear test specimen dimensions and anti-buckling fixture

\section{RESULTS AND DISCUSSIONS}

\subsection{Sem Analysis of PSF Nanofibers}

SEM images of pure PSF and $2 \mathrm{wt} \% \mathrm{SiC}-\mathrm{Fe}_{3} \mathrm{O}_{4} / \mathrm{PSF}$ hybrid PSF electrospun nanofibers are shown in Figure $\mathbf{4 a}$ and

Figure $4 \mathrm{~b}$. Nanofiber networks with a continuous and homogeneous form were obtained by the electrospinning process. The diameters of pure and hybrid nanofibers are between 300 and $500 \mathrm{~nm}$. It is seen that there is no significant change in diameters and morphological properties of PSF nanofibers with $2 \mathrm{wt} \% \quad \mathrm{SiC}_{-}-\mathrm{Fe}_{3} \mathrm{O}_{4}$ nanoparticles addition. 

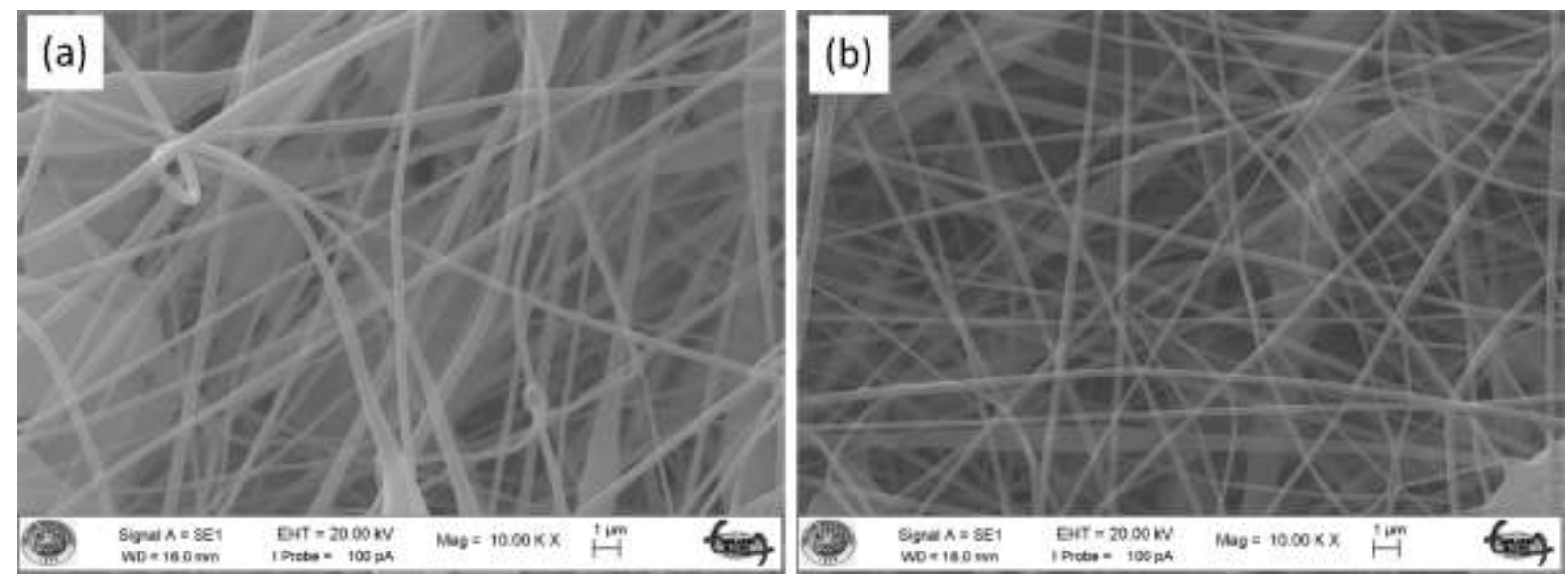

Figure 4. SEM images of (a) Pure PSF, (b) $2 \mathrm{wt} \% \mathrm{SiC} / \mathrm{Fe}_{3} \mathrm{O}_{4} / \mathrm{PSF}$ electrospun nanofibers.

\subsection{Mechanical Tests}

Effects of $\mathrm{SiC}-\mathrm{Fe}_{3} \mathrm{O}_{4}$ nanoparticles addition to PSF solution in different concentrations on the tensile properties of electrospun PSF nanofibers are shown in Figure 5 and Table 1. In the stress-strain curves of the nanofiber mats in Figure 5, it is clearly seen that the nanoparticle doped hybrid nanofibers are positively separated from the pure PSF nanofibers until the breaking point. Compared to pure PSF nanofiber mats, no significant decrease in ductility was observed in $1 \% \quad \mathrm{SiC}-\mathrm{Fe}_{3} \mathrm{O}_{4} / \mathrm{PSF}$ hybrid nanofiber mats. However, the elongation at break in $2 \% \quad \mathrm{SiC} \mathrm{Fe}_{3} \mathrm{O}_{4} / \mathrm{PSF}$ hybrid nanofiber mats decreased by $13 \%$, resulting in a significant loss in ductile deformation behavior.

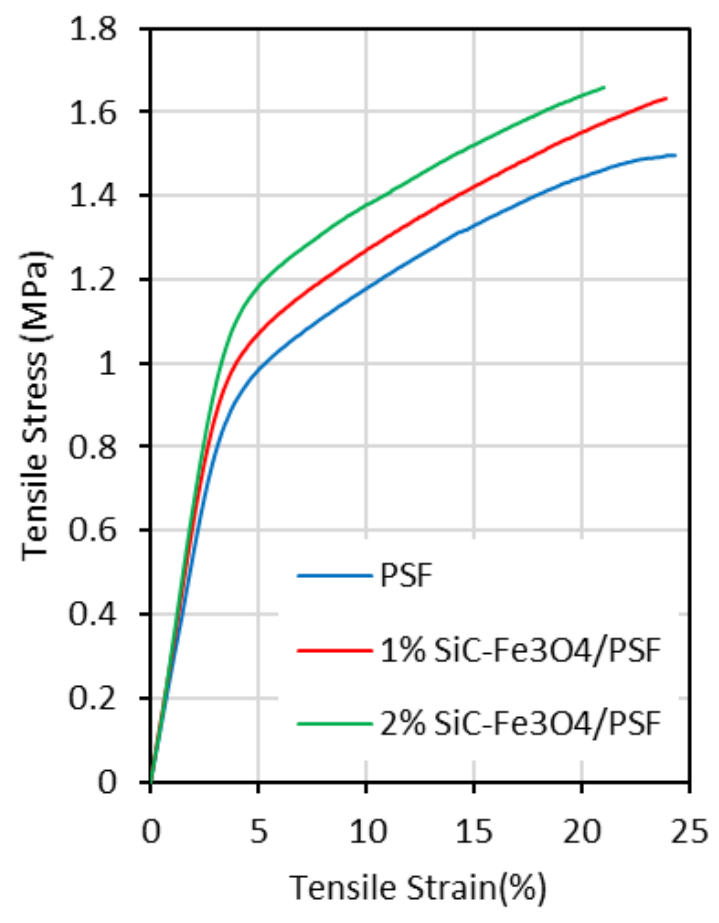

Figure 5. Tensile stress-strain curves of nanofiber mats 
Considering the tensile strengths and Young's modulus values presented in Table 1, adding $1 \mathrm{wt} \%$ $\mathrm{SiC}-\mathrm{Fe}_{3} \mathrm{O}_{4}$ nanoparticles into PSF nanofibers enhanced the tensile strength by $5 \%$ and Young's modulus by $27 \%$. Moreover, $2 \mathrm{wt} \% \mathrm{SiC}-\mathrm{Fe}_{3} \mathrm{O}_{4} / \mathrm{PSF}$ hybrid nanofiber mats reached the highest tensile strength and Young's modulus values with an increase of $7.9 \%$ and $28.7 \%$, respectively.

Table 1. Tensile properties of nanofiber mats

\begin{tabular}{|c|c|c|}
\hline & $\begin{array}{c}\text { Tensile } \\
\text { Strength } \\
(\mathrm{Mpa}) \\
\end{array}$ & $\begin{array}{l}\text { Young's } \\
\text { Modulus } \\
(\mathrm{Mpa}) \\
\end{array}$ \\
\hline PSF & $1.54 \pm 0.03$ & $26.21 \pm 0.26$ \\
\hline $1 \mathrm{wt} \% \mathrm{SiC}-\mathrm{Fe}_{3} \mathrm{O}_{4} / \mathrm{PSF}$ & $1.62 \pm 0.08$ & $33.27 \pm 1.89$ \\
\hline $2 \mathrm{wt} \% \mathrm{SiC}-\mathrm{Fe}_{3} \mathrm{O}_{4} / \mathrm{PSF}$ & $1.66 \pm 0.09$ & $33.75 \pm 2.32$ \\
\hline
\end{tabular}

Figure 6 shows the compressive stress-strain curves of reference and nanofiber interleaved composite laminates. The non-linear regions formed at the beginning of loading in the stress-strain curves of composites are toe regions caused by loosening, alignment, or seating of the specimens until the specimen is fully positioned between steel plates. The incorporation of PSF nanofiber mats between plies improved the compressive strength of glass/epoxy composite laminates. The reference composite laminate had a compressive strength of $210 \mathrm{MPa}$. Pure PSF, 1 wt $\% \mathrm{SiC}-\mathrm{Fe}_{3} \mathrm{O}_{4} / \mathrm{PSF}$ nanofiber interleaved laminates reached the compressive strength values of $264 \mathrm{MPa}$ and $265 \mathrm{MPa}$, respectively, increasing by approximately 26\%. $2 \mathrm{wt} \% \quad \mathrm{SiC}-\mathrm{Fe}_{3} \mathrm{O}_{4} / \mathrm{PSF}$ nanofibers slightly decreased the compressive strength by $2 \%$ compared to pure PSF nanofibers. Relatively ductile PSF nanofibers made the interlaminar resin-rich regions tougher. Thus, nanofiber interleaving increased the ultimate compressive strain by up to $23 \%$ compared to the reference laminate. There was no considerable effect of $1 \mathrm{wt} \%$ and $2 \mathrm{wt} \% \mathrm{SiC}_{-}-\mathrm{Fe}_{3} \mathrm{O}_{4}$ nanoparticles addition into PSF nanofibers on the compressive strength of nanofiber interleaved laminates.

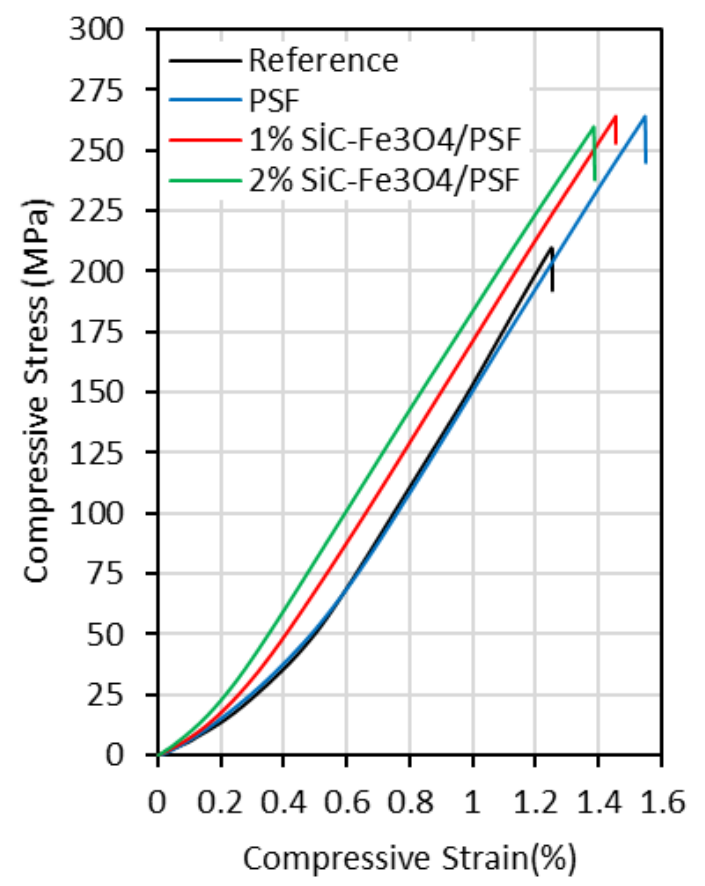

Figure 6. Compressive stress-strain curves of reference and nanofiber interleaved composite laminates 
The influence of nanofiber interleaving on interlaminar shear strengths of glass/epoxy composite laminates is shown in Figure 7. The interlaminar shear strength of reference glass/epoxy composite laminates was $41.7 \mathrm{MPa}$. Pure PSF, $1 \mathrm{wt} \%$, and $2 \mathrm{wt} \% \mathrm{SiC}_{-} \mathrm{Fe}_{3} \mathrm{O}_{4} / \mathrm{PSF}$ nanofibers enhanced the interlaminar shear strength by $6.9 \%, 10 \%$, and $12.4 \%$, respectively. $\mathrm{SiC}_{-}-\mathrm{Fe}_{3} \mathrm{O}_{4}$ nanoparticles doped PSF nanofibers provided further improvement in interlaminar shear resistance than that of the PSF nanofibers. $1 \mathrm{wt} \%$ and $2 \mathrm{wt} \% \mathrm{SiC}_{-} \mathrm{Fe}_{3} \mathrm{O}_{4} / \mathrm{PSF}$ hybrid nanofibers increased the interlaminar shear strength by $3 \%$ and $5 \%$, respectively, compared to pure PSF nanofibers.

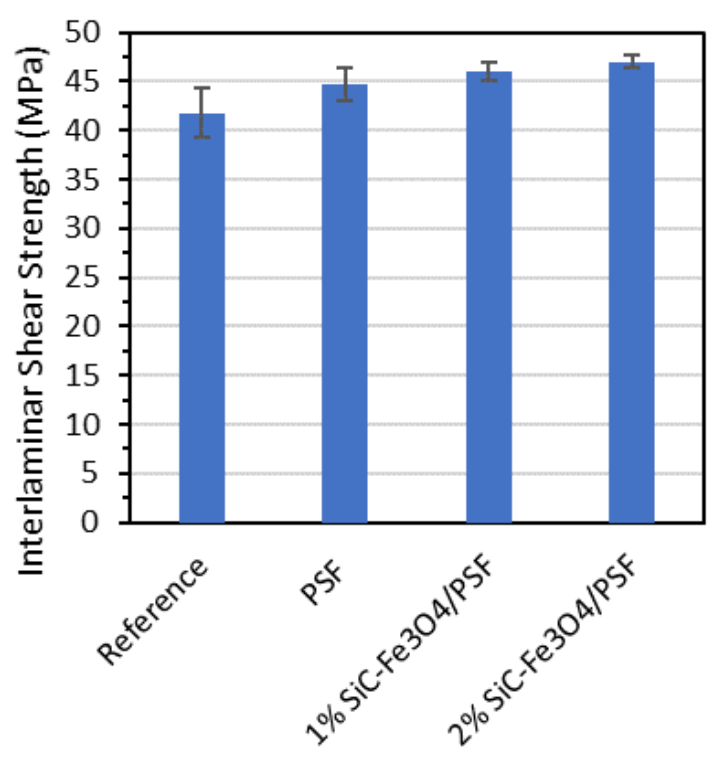

Figure 7. Interlaminar shear strength of reference and nanofiber interleaved composite laminates

\section{CONCLUSIONS}

In this study, pure and $\mathrm{SiC}-\mathrm{Fe}_{3} \mathrm{O}_{4}$ nanoparticles doped PSF nanofibers were produced by the electrospinning method. Electrospun nanofibers were interleaved in glass/epoxy composites laminates to determine their effects on the compressive and interlaminar shear properties of the laminates. In summary,

The addition of $\mathrm{SiC}-\mathrm{Fe}_{3} \mathrm{O}_{4}$ nanoparticles into PSF nanofibers improved tensile properties of nanofiber mats. $2 \mathrm{wt} \% \mathrm{SiC}_{-} \mathrm{Fe}_{3} \mathrm{O}_{4}$ loading into PSF nanofibers provided the highest increase in the tensile strength and Young modulus by $7.9 \%$ and $28.7 \%$, respectively.

$1 \mathrm{wt} \% \mathrm{SiC}-\mathrm{Fe}_{3} \mathrm{O}_{4} / \mathrm{PSF}$ hybrid nanofibers increased the compressive strength by up to about $26 \%$ compared to reference laminates. However, it was observed that there was no significant difference in compressive strengths between hybrid and pure PSF nanofiber interleaved laminates.

The maximum improvement in the interlaminar shear strength was achieved by $2 \mathrm{wt} \% \mathrm{SiC}-\mathrm{Fe}_{3} \mathrm{O}_{4} / \mathrm{PSF}$ hybrid nanofibers with an increase of $12.4 \%$.

Incorporation of pure PSF nanofibers and $\mathrm{SiC}_{-} \mathrm{Fe}_{3} \mathrm{O}_{4} / \mathrm{PSF}$ hybrid nanofibers between plies considerably enhanced compressive and interlaminar shear strength of glass/epoxy composites. 


\section{CONFLICT OF INTEREST}

The authors stated that there are no conflicts of interest regarding the publication of this article.

\section{REFERENCES}

[1] Wang RM, Zheng SR, Zheng YG. Polymer Matrix Composites and Technology: Elsevier Science, 2011.

[2] Mallick PK. Fiber-reinforced composites: materials, manufacturing, and design: CRC press, 2007.

[3] De Schoenmaker B, Van der Heijden S, De Baere I, Van Paepegem W, De Clerck K. Effect of electrospun polyamide 6 nanofibres on the mechanical properties of a glass fibre/epoxy composite. Polymer Testing 2013; 32: 1495-1501.

[4] Palazzetti R, Zucchelli A. Electrospun nanofibers as reinforcement for composite laminates materials - A review. Composite Structures 2017; 182: 711-727.

[5] Dzenis Y, Reneker D. Delamination resistant composites prepared by small fibre reinforcement at ply interfaces. Patent US6265333 B 2001; 1.

[6] Molnár K, Mészáros L, Koštáková E. The effect of needleless electrospun nanofibrous interleaves on mechanical properties of carbon fabrics/epoxy laminates. Express Polymer Letters 2014; 8: 62-72.

[7] Daelemans L, van der Heijden S, De Baere I, Rahier H, Van Paepegem W, De Clerck K. Using aligned nanofibres for identifying the toughening micromechanisms in nanofibre interleaved laminates. Composites Science and Technology 2016; 124: 17-26.

[8] Beylergil B, Tanoğlu M, Aktaş E. Enhancement of interlaminar fracture toughness of carbon fiber-epoxy composites using polyamide-6,6 electrospun nanofibers. Journal of Applied Polymer Science 2017; 134.

[9] Eskizeybek V, Yar A, Avc1 A. CNT-PAN hybrid nanofibrous mat interleaved carbon/epoxy laminates with improved Mode I interlaminar fracture toughness. Composites Science and Technology 2018; 157: 30-39.

[10] Saghafi H, Brugo T, Minak G, Zucchelli A. The effect of PVDF nanofibers on mode-I fracture toughness of composite materials. Composites Part B: Engineering 2015; 72: 213-216.

[11] Beylergil B, Tanoğlu M, Aktaş E. Modification of Carbon Fibre/Epoxy Composites by Polyvinyl Alcohol (PVA) Based Electrospun Nanofibres. Advanced Composites Letters 2016; 25: 69-76.

[12] Li G, Li P, Zhang C, Yu Y, Liu H, Zhang S, et al. Inhomogeneous toughening of carbon fiber/epoxy composite using electrospun polysulfone nanofibrous membranes by in situ phase separation. Composites Science and Technology 2008; 68: 987-994.

[13] Li G, Li P, Yu Y, Jia X, Zhang S, Yang X, et al. Novel carbon fiber/epoxy composite toughened by electrospun polysulfone nanofibers. Materials Letters 2008; 62: 511-514. 
[14] Li P, Liu D, Zhu B, Li B, Jia X, Wang L, et al. Synchronous effects of multiscale reinforced and toughened CFRP composites by MWNTs-EP/PSF hybrid nanofibers with preferred orientation. Composites Part A: Applied Science and Manufacturing 2015; 68: 72-80.

[15] Metin F, Avc1 A. In-plane quasi-static and out-of-plane dynamic behavior of nanofiber interleaved glass/epoxy composites and finite element simulation. Composite Structures 2021; 270: 114085 .

[16] Dzenis Y. Structural Nanocomposites. Science 2008; 319: 419-420.

[17] Anand A, Kumar N, Harshe R, Joshi M. Glass/epoxy structural composites with interleaved nylon 6/6 nanofibers. Journal of Composite Materials 2016; 51: 3291-3298.

[18] Liu F, Guo R, Shen M, Wang S, Shi X. Effect of Processing Variables on the Morphology of Electrospun Poly[(lactic acid)-co-(glycolic acid)] Nanofibers. Macromolecular Materials and Engineering 2009; 294: 666-672. 